\title{
Advances in Intelligent Systems and Computing
}

Volume 256

\section{Series Editor}

Janusz Kacprzyk, Polish Academy of Sciences, Warsaw, Poland e-mail: kacprzyk@ibspan.waw.pl 


\section{About this Series}

The series "Advances in Intelligent Systems and Computing" contains publications on theory, applications, and design methods of Intelligent Systems and Intelligent Computing. Virtually all disciplines such as engineering, natural sciences, computer and information science, ICT, economics, business, e-commerce, environment, healthcare, life science are covered. The list of topics spans all the areas of modern intelligent systems and computing.

The publications within "Advances in Intelligent Systems and Computing" are primarily textbooks and proceedings of important conferences, symposia and congresses. They cover significant recent developments in the field, both of a foundational and applicable character. An important characteristic feature of the series is the short publication time and world-wide distribution. This permits a rapid and broad dissemination of research results.

\section{Advisory Board}

Chairman

Nikhil R. Pal, Indian Statistical Institute, Kolkata, India

e-mail: nikhil@isical.ac.in

Members

Emilio S. Corchado, University of Salamanca, Salamanca, Spain e-mail: escorchado@usal.es

Hani Hagras, University of Essex, Colchester, UK

e-mail: hani@essex.ac.uk

László T. Kóczy, Széchenyi István University, Győr, Hungary

e-mail: koczy@sze.hu

Vladik Kreinovich, University of Texas at El Paso, El Paso, USA

e-mail: vladik@utep.edu

Chin-Teng Lin, National Chiao Tung University, Hsinchu, Taiwan

e-mail: ctlin@mail.nctu.edu.tw

Jie Lu, University of Technology, Sydney, Australia

e-mail: Jie.Lu@uts.edu.au

Patricia Melin, Tijuana Institute of Technology, Tijuana, Mexico

e-mail: epmelin@hafsamx.org

Nadia Nedjah, State University of Rio de Janeiro, Rio de Janeiro, Brazil

e-mail:nadia@eng.uerj.br

Ngoc Thanh Nguyen, Wroclaw University of Technology, Wroclaw, Poland

e-mail: Ngoc-Thanh.Nguyen@pwr.edu.pl

Jun Wang, The Chinese University of Hong Kong, Shatin, Hong Kong

e-mail: jwang@mae.cuhk.edu.hk 
Mohammad S. Obaidat · Joaquim Filipe

Janusz Kacprzyk · Nuno Pina

Editors

\section{Simulation and Modeling \\ Methodologies, Technologies and Applications}

International Conference, SIMULTECH 2012

Rome, Italy, July 28-31, 2012

Revised Selected Papers

说 Springer 


\section{Editors}

Mohammad S. Obaidat

Monmouth University

New Jersey

USA

\section{Joaquim Filipe}

Polytechnic Institute of Setúbal/INSTICC

Setúbal

Portugal

\author{
Janusz Kacprzyk \\ Polish Academy of Sciences \\ Systems Research Institute \\ Warsaw \\ Poland \\ Nuno Pina \\ Superior School of Technology of \\ Setúbal/IPS \\ Setúbal \\ Portugal
}

ISSN 2194-5357

ISBN 978-3-319-03580-2

DOI 10.1007/978-3-319-03581-9

Springer Cham Heidelberg New York Dordrecht London

\author{
ISSN 2194-5365 (electronic) \\ ISBN 978-3-319-03581-9 (eBook)
}

Library of Congress Control Number: 2013954678

(c) Springer International Publishing Switzerland 2014

This work is subject to copyright. All rights are reserved by the Publisher, whether the whole or part of the material is concerned, specifically the rights of translation, reprinting, reuse of illustrations, recitation, broadcasting, reproduction on microfilms or in any other physical way, and transmission or information storage and retrieval, electronic adaptation, computer software, or by similar or dissimilar methodology now known or hereafter developed. Exempted from this legal reservation are brief excerpts in connection with reviews or scholarly analysis or material supplied specifically for the purpose of being entered and executed on a computer system, for exclusive use by the purchaser of the work. Duplication of this publication or parts thereof is permitted only under the provisions of the Copyright Law of the Publisher's location, in its current version, and permission for use must always be obtained from Springer. Permissions for use may be obtained through RightsLink at the Copyright Clearance Center. Violations are liable to prosecution under the respective Copyright Law.

The use of general descriptive names, registered names, trademarks, service marks, etc. in this publication does not imply, even in the absence of a specific statement, that such names are exempt from the relevant protective laws and regulations and therefore free for general use.

While the advice and information in this book are believed to be true and accurate at the date of publication, neither the authors nor the editors nor the publisher can accept any legal responsibility for any errors or omissions that may be made. The publisher makes no warranty, express or implied, with respect to the material contained herein.

Printed on acid-free paper

Springer is part of Springer Science+Business Media (www.springer.com) 


\section{Preface}

This book includes extended and revised versions of a set of selected papers from the 2012 International Conference on Simulation and Modeling Methodologies, Technologies and Applications (SIMULTECH 2012) which was sponsored by the Institute for Systems and Technologies of Information, Control and Communication (INSTICC) and held in Rome, Italy. SIMULTECH 2012 was technically co-sponsored by the Society for Modeling \& Simulation International (SCS), GDR I3, Lionphant Simulation, Simulation Team and IFIP and held in cooperation with AIS Special Interest Group of Modeling and Simulation (AIS SIGMAS) and the Movimento Italiano Modellazione e Simulazione (MIMOS).

This conference brings together researchers, engineers, applied mathematicians and practitioners interested in the advances and applications in the field of system simulation. We believe the papers here published, demonstrate new and innovative solutions, and highlight technical problems that are challenging and worthwhile.

SIMULTECH 2012 received 125 paper submissions from 38 countries in all continents. A double blind paper review was performed by the Program Committee members, all of them internationally recognized in one of the main conference topic areas. After reviewing, only 38 papers were selected to be published and presented as full papers, i.e. completed work ( 10 pages in proceedings/30' oral presentations) and 26 papers, describing work-in-progress, were selected as short papers for $20^{\prime}$ oral presentation. Furthermore there were also 10 papers presented as posters. The full-paper acceptance ratio was thus $30 \%$, and the total oral paper acceptance ratio was less than $44 \%$.

The papers included in this book were selected from those with the best reviews taking also into account the quality of their presentation at the conference, assessed by the session chairs. Therefore, we hope that you find the papers included in this book interesting, and we trust they may represent a helpful reference.

We wish to thank all those who supported and helped to organize the conference. On behalf of the conference Organizing Committee, we would like to thank the authors, whose work mostly contributed to a very successful conference and the members of the Program Committee, whose expertise and diligence were instrumental to ensure the quality of final contributions. We also wish to thank all the members of the Organizing 
Committee whose work and commitment were invaluable. Thanks also are due to the organizations that technically co-sponsored the conference. Last but not least, we would like to thank INSTICC for sponsoring and organizing the conference.

September 2013

Mohammad S. Obaidat Joaquim Filipe Janusz Kacprzyk

Nuno Pina 


\section{Organization}

\section{Conference Chair}

Mohammad S. Obaidat

\section{Program Co-chairs}

Nuno Pina

Janusz Kacprzyk

\section{Organizing Committee}

Helder Coelhas

Andreia Costa

Bruno Encarnação

Carla Mota

Raquel Pedrosa

Vitor Pedrosa

Cláudia Pinto

Susana Ribeiro

José Varela

Pedro Varela

\section{Program Committee}

Erika Ábrahám, Germany Manuel Alfonseca, Spain Giulia Andrighetto, Italy Jan Awrejcewicz, Poland Gianfranco Balbo, Italy Simonetta Balsamo, Italy Isaac Barjis, USA
Monmouth University, USA

\author{
EST-Setúbal/IPS, Portugal \\ Systems Research Institute - Polish Academy \\ of Sciences, Poland
}

Ana Isabel Barros, The Netherlands Fernando Barros, Portugal Ildar Batyrshin, Mexico Lucian Bentea, Norway Marenglen Biba, Albania Louis Birta, Canada Ipek Bozkurt, USA 
Christiano Braga, Brazil

Srinivas Chakravarthy, USA

Naoufel Cheikhrouhou, Switzerland

E. Jack Chen, USA

Jean-Yves Choley, France

Ricardo Choren, Brazil

Lawrence Chung, USA

Bruno Ciciani, Italy

Claudio Cioffi-Revilla, USA

Kendra Cooper, USA

Andrea D'Ambrogio, Italy

Gabriella Dellino, Italy

Atakan Dogan, Turkey

Werner Dubitzky, UK

Stephan Eidenbenz, USA

Andreas Ernst, Germany

Roland Ewald, Germany

Denis Filatov, Mexico

Paul Fishwick, USA

Ian Flood, USA

José Manuel Galán, Spain

Nicolas R. Gauger, Germany

Nikolaos Geroliminis, Switzerland

Charlotte Gerritsen, The Netherlands

Daniele Gianni, The Netherlands

Brian Goldiez, USA

Alexandra Grancharova, Bulgaria

Zhi Han, USA

Monika Heiner, Germany

Brian Hollocks, UK

Polly Huang, Taiwan

Eric S. Imsand, USA

Mhamed Itmi, France

Mura Ivan, Italy

Luis Izquierdo, Spain

Segismundo Samuel Izquierdo, Spain

András Jávor, Hungary

Hans Jense, The Netherlands

Cara Kahl, Germany

Korina Katsaliaki, Greece

Peter Kemper, USA

Juš Kocijan, Slovenia

Petia Koprinkova-Hristova, Bulgaria

Samuel Kounev, Germany

Raymond Kristiansen, Norway
Jirí Kunovský, Czech Republic

Stephanie Jane Lackey, USA

Béla Lakatos, Hungary

Kennard Laviers, USA

Loo Hay Lee, Singapore

Sanghyun Lee, USA

Johannes Lüthi, Austria

Emilio Jiménez Macías, Spain

Carla Martin-Villalba, Spain

Radek Matušu, Czech Republic

Yuri Merkuryev, Latvia

Adel Mhamdi, Germany

Qi Mi, USA

Federico Milani, Italy

Gabriele Milani, Italy

Michael Möhring, Germany

Jairo Montoya-Torres, Colombia

Jairo R. Montoya-Torres, Colombia

Spyridon Mouroutsos, Greece

Navonil Mustafee, UK

Ines Mynttinen, Germany

Àngela Nebot, Spain

Manuel Noguera, Spain

Michael J. North, USA

James J. Nutaro, USA

Peter Csaba Ölveczky, Norway

Stephan Onggo, UK

Ioannis Paraskevopoulos, UK

James Parker, Canada

Ana Peleteiro, Spain

Petr Peringer, Czech Republic

L. Felipe Perrone, USA

H. Pierreval, France

Katalin Popovici, USA

Francesco Quaglia, Italy

Jacinto A. Dávila Quintero, Venezuela

Stanislav Racek, Czech Republic

Manuel Resinas, Spain

M. R. Riazi, Kuwait

José Risco-Martín, Spain

Stewart Robinson, UK

Theresa Roeder, USA

Paolo Romano, Portugal

Maarouf Saad, Canada

Jean-François Santucci, France 
Rune Schlanbusch, Norway

Avraham Shtub, Israel

Yuri Skiba, Mexico

Jaroslav Sklenar, Malta

Yuri Sotskov, Belarus

James C. Spall, USA

Flaminio Squazzoni, Italy

Giovanni Stea, Italy

Steffen Straßburger, Germany

Nary Subramanian, USA

Claudia Szabo, Australia

Antuela A. Tako, UK

Elena Tànfani, Italy

Pietro Terna, Italy

Emmanuel Tsekleves, UK

Bruno Tuffin, France

Alfonso Urquia, Spain

Mayerlin Uzcategui, Venezuela

\section{Auxiliary Reviewers}

Rogerio Batista, Brazil

Xin Chen, Germany

Florian Corzilius, Germany

\section{Invited Speakers}

David M. Nicol

Tuncer Ören

Simon Taylor

Anthony John Jakeman
Timo Vepsäläinen, Finland

Anil Vullikanti, USA

Natalie van der Wal, The Netherlands

Frank Werner, Germany

Philip A.Wilsey, USA

Muzhou Xiong, China

Nong Ye, USA

Levent Yilmaz, USA

Gregory Zacharewicz, France

František Zboril, Czech Republic

Durk Jouke van der Zee,

The Netherlands

Yabing Zha, China

Lin Zhang, China

Laurent Zimmer, France

Armin Zimmermann, Germany

Konstantinos Zografos, Greece

Nils Jansen, Germany

Ely Miranda, Brazil
University of Illinois, Urbana-Champaign, USA

University of Ottawa, Canada

Brunel University, UK

Australian National University, Australia 


\section{Contents}

\section{Part I: Invited Papers}

The Richness of Modeling and Simulation and an Index of Its Body of Knowledge ...................................... 3

Tuncer Ören

Modelling for Managing the Complex Issue of Catchment-Scale Surface

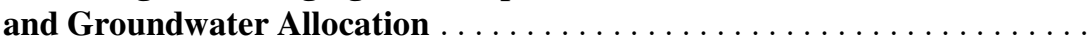

Anthony Jakeman, Rebecca Kelly (nee Letcher), Jenifer Ticehurst, Rachel Blakers, Barry Croke, Allan Curtis, Baihua Fu, Sondoss El Sawah, Alex Gardner, Joseph Guillaume, Madeleine Hartley, Cameron Holley, Patrick Hutchings, David Pannell, Andrew Ross, Emily Sharp, Darren Sinclair, Alison Wilson

\section{Part II: Papers}

Kinetic Analysis of the Coke Calcination Processes in Rotary Kilns . .

E.M. Elkanzi, F.S. Marhoon, M.J. Jasim

Behavior of Elastomeric Seismic Isolators Varying Rubber Material and Pad Thickness: A Numerical Insight . . . . . . . . . . . . . . . . . . . . . . .

Gabriele Milani, Federico Milani

Numerical Simulation of Coastal Flows in Open Multiply-Connected

Irregular Domains

Yuri N. Skiba, Denis M. Filatov

System Dynamics and Agent-Based Simulation for Prospective Health Technology Assessments .

Anatoli Djanatliev, Peter Kolominsky-Rabas, Bernd M. Hofmann, Axel Aisenbrey, Reinhard German 
Simple and Efficient Algorithms to Get a Finer Resolution in a Stochastic

Discrete Time Agent-Based Simulation

Chia-Tung Kuo, Da-Wei Wang, Tsan-sheng Hsu

Numerical Study of Turbulent Boundary-Layer Flow Induced

by a Sphere Above a Flat Plate

Hui Zhao, Anyang Wei, Kun Luo, Jianren Fan

Airflow and Particle Deposition in a Dry Powder Inhaler: An Integrated CFD Approach

Jovana Milenkovic, Alexandros H. Alexopoulos, Costas Kiparissides

Solar Soldier: Virtual Reality Simulations and Guidelines for the Integration of Photovoltaic Technology on the Modern Infantry Soldier . . . . 141 Ioannis Paraskevopoulos, Emmanuel Tsekleves

Simulation and Realistic Workloads to Support the Meta-scheduling of Scientific Workflows

Sergio Hernández, Javier Fabra, Pedro Álvarez, Joaquín Ezpeleta

Dynamic Simulation of the Effect of Tamper Resistance on Opioid Misuse

Outcomes

Alexandra Nielsen, Wayne Wakeland

A Multi-GPU Approach to Fast Wildfire Hazard Mapping

Donato D'Ambrosio, Salvatore Di Gregorio, Giuseppe Filippone,

Rocco Rongo, William Spataro, Giuseppe A. Trunfio

Controlling Turtles through State Machines: An Application

to Pedestrian Simulation

Ilias Sakellariou

Stability Analysis of Climate System Using Fuzzy Cognitive Maps

Carlos Gay García, Iván Paz Ortiz

Fuzzy Models: Easier to Understand and an Easier Way to Handle

Uncertainties in Climate Change Research . . . . . . . . . . . . . . . . . . . 223

Carlos Gay García, Oscar Sánchez Meneses, Benjamín Martínez-López,

Àngela Nebot, Francisco Estrada

Small-Particle Pollution Modeling Using Fuzzy Approaches

Àngela Nebot, Francisco Mugica

Stochastic Resonance and Anti-cyclonic Rings in the Gulf of Mexico

Benjamín Martínez-López, Jorge Zavala-Hidalgo, Carlos Gay García

On Low-Fidelity Model Selection for Antenna Design Using

Variable-Resolution EM Simulations

Slawomir Koziel, Stanislav Ogurtsov, Leifur Leifsson 
An X-FEM Based Approach for Topology Optimization of Continuum

Structures

Meisam Abdi, Ian Ashcroft, Ricky Wildman

Collaborative Optimization Based Design Process for Process

Engineering ...

Mika Strömman, Ilkka Seilonen, Kari Koskinen

Hydrodynamic Shape Optimization of Fishing Gear Trawl-Doors

Leifur Leifsson, Slawomir Koziel, Eirikur Jonsson

Wing Aerodynamic Shape Optimization by Space Mapping

Leifur Leifsson, Slawomir Koziel, Eirikur Jonsson

Efficient Design Optimization of Microwave Structures Using Adjoint

Sensitivity

Slawomir Koziel, Leifur Leifsson, Stanislav Ogurtsov

Author Index 